\author{
И. В. Зыкова \\ Институт языкознания РАН \\ (Россия, Москва) \\ zykova_iv@mail.ru
}

\title{
ЯЗЫКОВАЯ ИГРА В КОНСТРУИРОВАНИИ ПОЭТИКИ КОМЕДИЙНОГО КИНОДИСКУРСА*
}

Статья посвящена проблеме разработки теории и методологии изучения поэтики кинодискурса, особой значимостью в формировании которой обладает креативное использование языковых образных средств. В статье предпринимается попытка обосновать возможность рассмотрения поэтики кинодискурса как особой области научного поиска, берущей свое начало в работах представителей формализма. С этой целью анализируются исторический контекст возникновения и развития поэтики кино, особенности подхода русских формалистов к искусству и литературе, утверждающего примат игры и эксперимента в любом виде творчества, в кинотворчестве в частности, что логически приводит к постановке вопроса о релевантности языковой игры в последнем. Принимая во внимание видо-жанровое разнообразие кинодискурса, изучение языковой игры как фактора построения его поэтики проводится на материале отечественных кинокомедий 1960-х гг. В результате исследования выявляется ведущая роль такой разновидности языковой игры, как фразеоигра. В статье описываются шесть основных стратегий модификации фразеологизмов, применяемых в анализируемых кинокомедиях. Особое внимание уделяется свойственной поэтике кинодискурса стратегии визуализации фразеологических единиц, осуществляемой с помощью монтажа кинокадров. Проведенное исследование приводит к выводу о том, что языковые единицы, «преобразованные» языковой игрой, формируют особый пласт художественных средств в поэтике комедийного кинодискурса.

Ключевые слова: кинодискурс, поэтика, языковая игра, фразеология, фразеоигра, лингвокреативность, кинокомедия.

В последние десятилетия наблюдается существенное усиление интереса со стороны филологических наук к изучению кинодискурса (или дискурса кино, дискурса

* Исследование выполнено за счет гранта Российского научного фонда (проект №19-1800040) в Институте языкознания РАН. 
кинофильмов). Современный методологический арсенал филологии и интенсивное развитие общей теории киноискусства в искусствоведении, обусловленное стремительно эволюционирующей киноиндустрией, создают особое поле притяжения для данных наук, в рамках которого осуществляется формирование новых областей научного поиска. Одним из результатов сопряжения филологии (в частности, лингвистики) и искусствоведения (в частности, киноведения), способствующего возникновению новых междисциплинарных направлений, является, с нашей точки зрения, «поэтика кинодискурса», которая видится нам закономерным звеном в системе такой специализации научного знания, как «поэтика > поэтика кино $>$ поэтика кинодискурса». Как указывает А.И. Пиотровский, «всякая теория кино рано или поздно наталкивается на необходимость отмежевания от поэтики соседних искусств - литературы и театра, искусств старинных, владеющих устойчивой, исторически сложившейся теорией» [Пиотровский 2016: 158].

Изучение поэтики кинодискурса зиждется на необходимости учета и анализа нескольких ее взаимосвязанных внешних и внутренних планов: научных истоков и исторического контекста становления, ее внутренней дифференциации и лингвистических факторов ее построения и организации.

Как известно, потенциал изучения и вектор(ы) освоения любой области научного познания определяются в значительной мере ее научными истоками или научными основаниями. Уходя корнями в античную философию, поэтика кинодискурса берет свое непосредственное начало в исследованиях формальной школы. В 1927 г. выходит в свет сборник научных статей представителей и сторонников формализма под названием «Поэтика кино», направленный главным образом на осмысление природы и отличительных особенностей кинопроизведения, в особенности роли и значимости в его структуре вербального компонента («слышимого слова», надписей или титров) (см., например, [Эйхенбаум 2016]).

Вышедшая книга отражала дух своего времени, примечательного каскадом глобальных событий, приведших к радикальным переменам в культуре, науке и обществе. Прежде всего, это время ускорения научно-технического прогресса, обусловившего стремительное развитие кинопромышленности. Кроме того, первая половина XX в. знаменательна предпринимавшимися попытками обосновать статус кино как одного из видов искусства наравне с театром, литературой, музыкой и другими искусствами (см., например, «Манифест семи искусств» Р. Канудо (1911)). Согласно [БРЭ], «освоение опыта других искусств вписывалось в общие процессы развития поэтики кино». Среди наиболее значимых черт этого времени необходимо также выделить становление новой культурной (авангардной) парадигмы, утверждающей новую систему ценностных координат в литературе и искусстве, доминантами в которой являются, по М. В. Умновой, релятивизм, эстетизм и динамика [Умнова 2013]. Автор, в частности, замечает, что «смена иерархического “верха” повела к тому, что в новой системе координат, где наивысший аксиологический статус получило эстетическое, интерес исследователей переместился из области толкований в область анализа поэтики» [Там же: 35], в область анализа поэтики кино в частности. 
Хотя поэтика кино не оформилась в свое время в отдельное научное направление, разрабатываемые в ее рамках идеи и концепции заложили фундамент и сформировали значительный потенциал для многовекторного и многомерного осмысления кино в последующие десятилетия как особого вида синтетического искусства и «языка» кино как сложного комплекса разнородных семиотических средств, определенным образом взаимодействующих друг с другом в процессе создания кинофильма (см., например, [Лотман 1973; Лотман, Цивьян 1994]). Следует отметить, что в разработке поэтики кино ее основатели - формалисты исходили из своего общего понимания нового искусства (в широком смысле), отличительной чертой которого является примат поэтического над практическим, эстетического над коммуникативным, инновационного над традиционным, невербального над вербальным (с последующим переосмыслением вербального и признания его равнозначной роли в создании кинопроизведения), низкого над высоким, неправильного над нормативным. По выражению Ю.Н. Тынянова, «...каждая "ошибка”, каждая “неправильность” нормативной поэтики есть - в потенции - новый конструктивный принцип...» [Тынянов 1977: 263]. Абсолютизация критериев новизны и инновационности, достижение которых опосредовано нарушениями норм и традиций, вкупе с «карнавальным мироощущением» (по Бахтину), свойственным формалистам, их ориентацией на перформативность и склонность к эпатажу приводят к культивированию значимости игры и эксперимента в любом виде творчества и, в частности, в кинотворчестве и в такой его неотъемлемой составляющей, как языковое творчество. О релевантности для представителей и сторонников формальной школы данных феноменов как источников инноваций свидетельствует также и их повышенное внимание к таким жанрам, как пародия, фельетон, анекдот, гротеск, к таким стилистическим средствам и фигурам речи, как парадокс, ирония, каламбур, а также введенные в научный обиход и разрабатываемые формалистами понятия и приемы, например, «новое зрение» (Ю.Н. Тынянов), «остранение» (В.Б. Шкловский), «эволюционная ценность» и др. Все эти факты в совокупности подводят нас к выводу о важной роли языковой игры в создании художественного произведения (в широком смысле) и, в частности, кинопроизведения (или кинофильма), возводя ее в ранг одного из весомых и действенных факторов поэтики последнего, понимаемой как совокупность разного рода принципов, приемов и средств создания художественной реальности и ее структуры, существующей в художественном пространстве и времени и отражающей определенную концепцию мира [Борев 2003].

Изучение языковой игры как фактора поэтики кинодискурса требует, несомненно, учета видо-жанрового разнообразия кино, обусловливающего соответствующее разнообразие типов кинодискурса.

С учетом исследуемой проблемы интерес представляет в первую очередь игровое кино и, следовательно, такой тип кинодискурса, как игровой кинодискурс. При определении его специфики и отличия от других основных видов киноискусства в [БРЭ] указывается, что «в игровом кино средствами исполнительского творчества воссоздаются реальные или вымышленные события, как правило, на основе специально 
написанного сценария либо переработки произведений литературы - документальной или художественной прозы, театральной драматургии и др.». По мере развития киноиндустрии в игровом кино формируются, как известно, различные жанры и поджанры, среди которых одно из ведущих положений с первых лет его истории занимает кинокомедия. Примечательно, что отличительная особенность поэтики кинокомедий состоит в изначально высоком статусе в ней вербального компонента, о чем писали еще представители формализма. Так, Б. М. Эйхенбаум замечает, что «опыт <...> указывает на то, что комические фильмы более других нуждаются в разговорных надписях, и надписи эти иногда значительно усиливают комический эффект <..>. Происходит это потому, что комизм вообще есть явление смысловое, тесно связанное поэтому со словом. Комическая фильма строится обычно на деталях отдельных положений, а детали эти могут “дойти” до зрителя только через посредство надписей» [Эйхенбаум 2016: 27], или через посредство включения «слышимого слова». Нацеленность на креативное использование языковых средств делает комедийный кинодискурс особо привлекательным с точки зрения изучения роли языковой игры и особенностей ее реализации в формировании его поэтики.

Таким образом, комедийный кинодискурс представляет собой особое пространство художественной реализации креативного потенциала языковой системы и выступает источником различных языковых новаций, отражающих своеобразие его поэтики. С учетом этого цель настоящего исследования заключается в анализе и систематизации прежде всего способов нестандартного, игрового, использования языковых средств в комедийном кинодискурсе. Материалом исследования на данном этапе послужили восемь отечественных кинокомедий известных кинорежиссеров, вышедших в 1960-х гг.: «Полосатый рейс» (1961), «Семь нянек» (1962), «Королева бензоколонки» (1962), «Три плюс два» (1963), «Добро пожаловать, или Посторонним вход воспрещен» (1964), «Дайте жалобную книгу» (1965), «Операция “Ы” и другие приключения Шурика» (1965), «Бриллиантовая рука» (1968). Общая продолжительность анализируемых кинофильмов составляет 692 минуты (11,5 часов).

Отдельно отметим, что кинокомедии данного периода были выбраны не случайно. В киноведении 60-е годы отмечаются как особая эпоха в развитии киноискусства, ознаменовавшаяся появлением инновационных подходов в сфере производства кинофильмов и разработкой целого ряда новых теорий и концепций, меняющих взгляд на природу кино и принципы его создания, делающих особый акцент на его функциях [Burch 1969; Mitry 1997]. Кинематографические эксперименты становятся доступными широкой публике; производятся фильмы, совмещающие в себе, в частности, элементы авангарда и массовой культуры. В отечественном киноискусстве 60-е годы - время эстетического обновления кино, развития «новых принципов строения фильма, нарушающих традиционные каноны киноповествования». Особо примечательно, что, согласно [БРЭ], «в экранном творчестве стали широко применяться самые разнообразные формы стилистической полифонии», например «коллажи цитат — пластических, музыкальных, титровых и текстовых», «разработка экранного внутреннего монолога» и т. д. В этот 
период отечественное киноискусство начинает выходить на новые рубежи в творчестве Анд. А. Тарковского, А. Ю. Германа, Г. Н. Данелии, Э. Г. Климова, П. Г. Чухрая, Э. А. Рязанова, Л.И. Гайдая и др. [Там же].

В отобранных для анализа кинокомедиях нами исследуются устный и письменный форматы кинодискурса: все звучащие монологи и диалоги киноперсонажей; названия кинолент, а также слова, фразы, текст, написанные на афишах и вывесках, в объявлениях и т.д., или отдельно представленные в кадре. Как показало проведенное исследование, особой значимостью в построении комедийного кинодискурса обладают фразеологизмы. Данный факт позволяет говорить о ведущей роли в формировании поэтики комедийного кинодискурса такой разновидности языковой игры, как фразеоигра [Зыкова 2017]. Модифицированные и немодифицированные фразеологизмы встречаются во всех рассмотренных нами фильмах и, к примеру, в фильме «Дайте жалобную книгу», продолжительность которого 85 минут, их число составляет более 200 единиц. В связи с этим представляется целесообразным далее остановиться отдельно на выявленных способах создания фразеоигры в рассматриваемых отечественных кинокомедиях.

Проводимое исследование убеждает нас в том, что различные преобразования базовых форм фразеологических единиц обусловлены одной из главных прагматических задач кинокомедии - «осмеяния» (в широком понимании) и попадают под определение «игровых». Соответственно, разного рода преобразования фразеологизмов в дискурсе комедийных фильмов можно считать случаями фразеоигры. Фразеоигра определяется в нашей работе как разного рода, разного типа и разного объема модификации фразеологизмов, создание которых направлено, главным образом, на достижение комического эффекта, вызывающего у реципиента-зрителя «комический» смех (или «смех ума») от обнаруженной комической «ситуации» (в широком смысле) и разрешенного в ней противоречия [НФЭ]. В дополнение к этому определению уместно также вспомнить слова Б. М. Эйхенбаума [2016] о том, что любое развертывание словесной метафоры является преимущественно пародийным приемом.

В первую очередь обращают на себя внимание сами названия фильмов, в которых присутствуют фразеологизмы и которые несут указание на их креативное использование и языковую игру. Например, название кинокомедии «Семь нянек» представляет собой редуцированную форму пословицы У семи нянек дитя без глазу. Посредством комбинирования двух ситуативных клише с противоположными значениями создается название с антитезой и парадоксом «Добро пожаловать, или Посторонним вход воспрещен», в котором добро пожаловать означает 'приветствие при встрече и вежливое приглашение зайти, прийти, приехать и проч.', а посторонним вход воспрещен - 'строгий запрет на вход, посещение какого-либо места'. Выразительность названия кинокомедии «Дайте жалобную книгу» обусловлена использованием в нем фразеологизма жалобная книга. Показательно, что названиями остальных кинокомедий являются словосочетания, обладающие достаточно высокой степенью идиоматичности (ср., например, «Полосатый рейс», «Бриллиантовая рука»). 
Согласно полученным данным, в дискурсе комедийного кино в значительном числе случаев фразеологизмы модифицируются посредством разного рода стратегий (подробнее о стратегиях см. [Зыкова 2015]). Приведем примеры шести основных стратегий, посредством которых осуществляется их обыгрывание в комедийном кинодискурсе и достигается определенный комический эффект.

Одной из наиболее частотных является стратегия «встраивания», представляющая собой преобразование базовой формы фразеологической единицы за счет включения в ее структуру одного и более новых компонентов (возможно целой фразы), например: (1) вести какой-либо образ жизни > (Шулейкин): Тигр, он ведет очень, ну просто очень ... хищный образ всей своей жсизни («Полосатый рейс»); (2) делать что-либо собственными руками > (Выступающий на собрании): А новое - это не то, что сделает для нас какой-нибудь там дяденька-новатор. Новое - это то, что предстоит нам сделать вот этими, вот собственными руками («Дайте жалобную книгу»).

Стратегия «приращение», направленная на расширение базовой формы фразеологизма путем препозиционного и/или постпозиционного добавления к ней новых компонентов, применяется в ходе построения кинодискурса в отношении следующих языковых единиц: (3) чувство юмора > (Ира): А что мне делать, если у меня такое чувство юмора повышенное («Семь нянек»); (4) катиться под гору $>$ (Афанасий Полосухин): Тяжелое у меня было детство. <...> [Oтеи] В шахте работал. ... Мать с горя выпивать стала. <... $>$ [Я] и покатился под гору, пока милиционер не остановил («Семь нянек»).

Фразеоигра может базироваться также и на стратегии «перекомпозиции», состоящей в намеренном изменении порядка расположения компонентов в базовой форме образа фразеологизмов по отношению друг к другу, например: (5) находить общий язык с кем-либо > (Официантка Клава): Иуйду! Уйду! Чем такие люди, так уж лучше звери. (Официантка Раечка): Ты с ними найдешь общий язык («Дайте жалобную книгу»); (6) играть на нервах (кого-либо) > (Водитель грузовика): Эй, куда смотришь? Куда смотришь? То милиция на нервах играет, а то... Тебе бьл в парикмахерской из пульверизатора прыскать («Королева бензоколонки»).

Стратегия «разбиение», заключающаяся в намеренном нарушении целостности базовой формы фразеологизма посредством разных способов (например, размещения одного из его компонентов в другом предложении) и в ряде случаев приводящая к образованию двух и более «альтернативных» фразеологизированных выражений, используется для достижения определенного комического эффекта в таком контексте, как: (7) откликнуться на чей-либо зов > (Кондаков): Ведь ты же откликнулась! (Никитин): На наш зов. (Татьяна Шумова): Зов? Рев! («Дайте жалобную книгу»).

Особой выразительностью обладает фразеоигра, основанная на стратегии «комбинирования», представляющей собой интегрирование в пределах одного сегмента кинодискурса нескольких фразеологизмов (в широком понимании), в частности, паремий: (8) (Прораб, обращаясь к Верзиле): ... учит народная мудрость - терпение и труд все перетрут - раз! Кончил дело - гуляй смело - два! Без труда 
не выловишь рыбку из пруда - три! Работа не волк-в лес не ... Нет, нет, это не надо («Операция “Ы” и другие приключения Шурика»).

Следует подчеркнуть, что установленные стратегии используются зачастую в разных сочетаниях друг с другом. Например, модификация фразеологизма откликнуться на чей-либо зов осуществляется не только за счет разбиения его базовой формы, но и посредством встраивания в его структуру новой лексемы «рев», заменяющей исходный компонент «зов» (см. пример 7).

Отдельного внимания заслуживает выявленная в ходе исследования особая, свойственная именно поэтике кинодискурса стратегия языковой игры - визуализация фразеологизмов, осуществляемая с помощью монтажа соответствующих кинокадров. В качестве примера рассмотрим применение данной стратегии к фразеологизму яблоку негде уnacmb, означающему '1) большое скопление людей; 2) очень тесно'.

В кинокомедии «Три плюс два» отправной точкой в «визуализации» анализируемого фразеологизма являются несколько кадров, на которых в разных ракурсах показан переполненный людьми пляж на морском побережье. Данные кадры сменяются другими, постепенно раскрывающими ситуацию, которая составляет основу образа рассматриваемого фразеологизма: по этому пляжу медленно идет мужчина, очень аккуратно и осторожно ступая между сидящими и лежащими на нем повсюду людьми. В одной руке мужчина держит перевернутую шляпу, наполненную до самого верха яблоками. В один момент одно из яблок выпадает из шляпы и, двигаясь вперед по воздуху рядом с идущим мужчиной, пытается упасть то в одном, то в другом, то в третьем и т. д. месте на пляже. Не найдя места, куда ему можно было бы упасть, яблоко в итоге возвращается в шляпу к мужчине.

Необходимо отметить, что специфика данной стратегии модификации фразеологизма яблоку негде упасть заключается в межсемиотическом переводе его содержания из вербальной в визуальную форму, которая при этом меняет его базовую (вербальную) форму за счет добавления к ней новых элементов, усиливающих его образность: яблоко не просто падает, оно летит по воздуху и возвращается через некоторое время на свое прежнее место. Кроме того, степень выразительности или экспрессивности фразеологизма повышается за счет сопровождающих его использование жестов и мимики людей на экране, звучания легкой (развлекательной) музыки, что способствует усилению и комического эффекта.

Языковая (точнее, фразеологическая) игра, базирующаяся на применении такого рода стратегии, выводит нас в область киносемантики, в которой одно из центральных мест занимает вопрос о природе и функциях кинометафоры. Данный вопрос требует отдельного рассмотрения, которое не входит в задачи настоящей статьи. В связи с этим отметим только некоторые из значимых для нашего исследования моментов.

Согласно [БРЭ], «еще в 1916 итальянские футуристы во главе с Ф. Т. Маринетти выпустили манифест, где утверждалось, что кино способно воплощать большинство тропов, известных в литературе». Авангардисты искали специфические для кино средства художественного выражения, недоступные другим искусствам 
(концепция «чистое кино»). В то же самое время Б. М. Эйхенбаум утверждает, что «кинометафора возможна только при условии опоры на словесную метафору» [Эйхенбаум 2016: 52]. Исследователь подчеркивает, что «зритель может понять ее только в том случае, если в его речевом запасе имеется соответствующее метафорическое выражение». Согласно автору, «материалом для кинометафор могут служить только ходячие словесные метафоры» [Там же]. В качестве примера Эйхенбаум приводит создание кинометафоры на базе фразеологизма смотреть сверху вниз на кого-либо в фильме «Шинель», описывая ее следующим образом: «в сцене между Акакием Акакиевичем и “значительным лицом” меняются ракурсы снизу, когда Акакий Акакиевич смотрит на “значительное лицо”, и сверху, когда “значительное лицо” кричит на Акакия Акакиевича» [Там же: 52]. В свою очередь Ю. М. Лотман и Ю.Г. Цивьян также подчеркивают, что простейшим способом создания метафоры в кино является заимствование из языка литературы. При этом, по мнению авторов, «это не означает, что в стилистическом мире <..> кинематографа $<\ldots>$ метафора невозможна. Метафорический перенос достигается здесь иными способами. Главный из них — пластическая метафора» [Лотман, Цивьян 1994: 171].

Подводя итог всему вышесказанному, подчеркнем, что сделанные на данном этапе исследования наблюдения свидетельствуют в пользу признания за языковой игрой статуса значимой движущей силы процесса построения поэтики комедийного кинодискурса. Согласно проведенному анализу, одним из фактов реализации языковой игры являются разного рода модификации фразеологизмов, представляющих собой образные, особо выразительные, эмоционально-окрашенные и культурно-специфичные единицы языковой системы. Как знаки специфической природы в своих модифицированных формах фразеологизмы призваны выполнять не только коммуникативную, но главным образом эстетическую и поэтическую функцию в создании художественной реальности комедийного фильма и в реализации художественного замысла его автора, основу которых составляет категория «комического». Языковые единицы, преобразованные языковой игрой, формируют особый пласт художественных средств в поэтике комедийного кинодискурса. Как видится, изучение природы, функций и стратегий языковой игры в комедийном кинодискурсе вносит также вклад в разработку проблемы киносемантики, в изучение специфики взаимодействия вербальных и невербальных форм ее воплощения.

\section{Литература}

Борев Ю. Б. Эстетика. Теория литературы: Энциклопедический словарь терминов. М.: Астрель, АСТ, 2003. 575 с.

БРЭ - Большая Российская энциклопедия. 2018. [Электронный ресурс]. URL: https://bigenc.ru/

Зыкова И. В. Концептосфера культуры и фразеология: Теория и методы лингвокультурологического изучения. М.: Ленанд, 2015. 380 с. 
Зыкова И. В. Метаязык лингвокультурологии: Константы и варианты. М.: Гнозис, $2017.752 \mathrm{c}$.

Лотман Ю.М. Семиотика кино и проблемы киноэстетики. Таллин: Ээсти Раамат, 1973. $135 \mathrm{c}$.

Лотман Ю.М., Цивьян Ю.Г. Диалог с экраном. Таллинн: Александра, 1994. $144 \mathrm{c}$.

HФЭ — Новая философская энциклопедия. [Электронный ресурc]. URL: https:// dic.academic.ru/dic.nsf/enc_philosophy/

Пиотровский А. И. К теории киножанров // Поэтика кино. Теоретические работы 1920-х гг. М.: Академический проект; Альма Матер, 2016. С. 158-184.

Тынянов Ю. Н. Поэтика. История литературы. Кино. М.: Наука, 1977. 574 с.

Умнова М.В. «Делать вещи нужные и веселые...» // Авангардные установки в теории литературы и критике ОПОЯЗа. М.: Прогресс-Традиция, 2013. 176 с.

Эйхенбаум Б. М. Проблемы киностилистики // Поэтика кино. Теоретические работы 1920-х гг. М.: Академический проект; Альма Матер, 2016. С. 14-53.

Burch N. Praxis du cinéma. Paris: Gallimard, 1969. 256 p.

Mitry J. The aesthetics and psychology of the cinema. Bloomington, 1997. $424 \mathrm{p}$.

\author{
I.V. Zykova \\ Institute of Linguistics of the Russian Academy of Sciences \\ (Russia, Moscow) \\ zykova_iv@mail.ru
}

\title{
LANGUAGE PLAY IN CONSTRUAL OF POETICS OF COMEDY FILM DISCOURSE
}

The paper is devoted to the discussion of the theory and methodology of studying the poetics of cinematic discourse and the creative use of language figurative means that plays an important role in its construal. It intends to show that the poetics of cinematic discourse can be regarded as a special field of research that stems from the formal school assumptions. As a starting point, the cultural events that influence the development of poetics of cinema are considered. Special attention is paid to the Russian formalists' approach to art and literature, in which such phenomena as play and experiment in any kind of art, including cinema, gain exceptional relevance. These assumptions lead on to the conclusion about the significance of the language play in cinematic art. Taking into account the existence of various types and genres of the cinematic discourse, the present study focuses on the analysis of the Russian comedy films released in the 1960s. The research conducted has revealed the high frequency of cases of phraseological play as a variety of language play in the discourse under study. Six main strategies of modifying phraseologisms for poetic purposes in the comedy films are described. Special attention is paid to the strategy of visualizing phraseologisms based on the combination 
of cinematic shots that may be regarded as a unique strategy of the cinematic discourse. The research findings allow to come to the conclusion that verbal units modified by language play form a special layer of expressive (artistic) means of the poetics of comedy film discourse.

Key words: cinematic discourse, poetics, language play, phraseology, phraseological play, linguistic creativity, comedy films.

\section{References}

Borev Yu. B. Estetika. Teoriya literatury: Enciklopedicheskij slovar' terminov [Aesthetics. Theory of literature: Encyclopedic dictionary of terms]. Moscow, Astrel', AST Publ., 2003. 575 p.

BRE - Bol'shaya Rossiiskaya entsiklopediya [Large Russian encyclopedia]. 2018. Avialable at: https://bigenc.ru/

Eikhenbaum B.M. [Problems of cinema stylistics]. Poetika kino. Teoreticheskie raboty 1920-x gg. [Poetics of cinema. Theoretical works of the 1920s]. Moscow, Akademicheskii Proekt; Al'ma Mater Publ., 2016, pp. 14-53. (In Russ.).

Lotman Yu. M. Semiotika kino i problemy kinoestetiki [Semiotics of cinema and problems of cinema aesthetics]. Tallin, Eesti Raamat Publ., 1973. 135 p.

Lotman Yu. M., Tsiv'yan Yu. G. Dialog s ekranom [A dialogue with the screen]. Tallinn, Aleksandra Publ., 1994. 144 p.

NFE - Novaya filosofskaya entsiklopediya [New philosophical encyclopedia]. [Electronic resource]. Available at: https://dic.academic.ru/dic.nsf/enc_philosophy/

Piotrovskii A. I. [Towards the theory of cinema genres]. Poetika kino. Teoreticheskie raboty 1920-x gg. [Poetics of cinema. Theoretical works of the 1920s]. Moscow, Akademicheskii Proekt; Al'ma Mater Publ., 2016, pp. 158-184. (In Russ.)

Tynyanov Yu. N. Poetika. Istoriya literatury. Kino [Poetics. History of literature. Cinema]. Moscow, Nauka Publ., 1977. 574 p.

Umnova M.V. "Delat' veshhi nuzhnye $i$ veselye..." / Avangardnye ustanovki v teorii literatury i kritike OPOYaZa ["Making things necessary and funny..." / Avant-garde prescriptions in the theory of literature and criticism of OPOYaZ]. Moscow, Progress Traditsiya Publ., 2013. 176 p.

Zykova I.V. Kontseptosfera kul'tury $i$ frazeologiya: Teoriya $i$ metody lingvokul'turologicheskogo izucheniya [The conceptual sphere of culture and phraseology: Theory and methods of linguocultural studies]. Moscow, Lenand Publ., 2015. 380 p.

Zykova I. V. Metayazyk lingvokul'turologii: Konstanty $i$ varianty [Metalanguage of linguoculturology: Constants and variants]. Moscow, Gnozis Publ., 2017. 752 p. 